\title{
Aspectos clínicos, hematológicos, citológicos, diagnóstico e tratamento de tumor venéreo transmissível em cão
}

\author{
Clinical, hematological, cytological, diagnosis and treatment aspects of transmissible venereal \\ tumor in dog
}

Aspectos clínicos, hematológicos, citológicos, diagnóstico y tratamiento del tumor venéreo

transmisible en perro

Recebido: 22/07/2021 | Revisado: 30/07/2021 | Aceito: 03/08/2021 | Publicado: 08/08/2021

Fabiana Carolina Miranda Rodrigues Morais
ORCID: https://orcid.org/0000-0002-8315-603X
Universidade da Amazônia, Brasil
E-mail: veterinariafabiana@ hotmail.com
Mayra Kevinly Guimarães Ferreira
ORCID: https://orcid.org/0000-0002-7602-8320
Universidade da Amazônia, Brasil
E-mail: mayra.kevinly18@gmail.com
Aryane Silva
ORCID: https://orcid.org/0000-0002-3279-703X
Universidade da Amazônia, Brasil
E-mail: anemedvet@ hotmail.com
Welligton Conceição da Silva
ORCID: https://orcid.org/0000-0001-9287-0465
Universidade Federal Rural da Amazônia, Brasil
E-mail: welligton.medvet@gmail.com
Lílian Kátia Ximenes Silva
ORCID: https://orcid.org/0000-0002-0790-1958
Universidade da Amazônia, Brasil
E-mail: silva_lilian@ yahoo.com.br

\begin{abstract}
Resumo
O Tumor Venéreo Transmissível (TVT) é uma neoplasia maligna, cuja transmissão geralmente é de caráter sexual, podendo ocorrer também por lambedura ou mordedura. O objetivo do trabalho foi relatar um caso clínico de TVT na região da genitália em um cão macho na cidade de Belém, Pará. O diagnóstico baseou-se no exame clínico (histórico clínico), laboratorial (hemograma) e citológico. O agente terapêutico utilizado foi o sulfato de vincristina, sendo bom prognóstico em $90 \%$ dos casos, quando o tratamento é realizado corretamente. Neste caso o tratamento demonstrou-se eficaz e houve regressão do tumor.
\end{abstract}

Palavras-chave: Canino; Reprodução; Neoplasia; Diagnóstico; Vincristina.

\begin{abstract}
The Transmissible Venereal Tumor (TVT) is a malignant neoplasm, whose transmission is usually sexual, and can also occur by licking or biting. The aim of this study was to report a clinical case of TVT in the genital region of a male dog in the city of Belém, Pará. The diagnosis was based on clinical (clinical history), laboratory (hemogram) and cytological examination. The therapeutic agent used was vincristine sulfate, with a good prognosis in $90 \%$ of the cases, when the treatment is carried out correctly. In this case, the treatment proved to be effective and the tumor regressed.
\end{abstract}

Keywords: Canine; Reproduction; Neoplasm; Diagnosis; Vincristine.

\section{Resumen}

El Tumor Venéreo Transmisible (TVT) es una neoplasia maligna, cuya transmisión suele ser sexual, y también puede ocurrir por lamido o mordisco. El objetivo de este estudio fue reportar un caso clínico de TVT en la región genital de un perro macho en la ciudad de Belém, Pará. El diagnóstico se basó en la clínica (historia clínica), laboratorio (hemograma) y examen citológico. El agente terapéutico utilizado fue el sulfato de vincristina, con buen pronóstico en el $90 \%$ de los casos, cuando el tratamiento se realiza correctamente. En este caso, el tratamiento demostró ser eficaz y el tumor retrocedió.

Palabras clave: Canino; Reproducción; Neoplasia; Diagnóstico; Vincristina. 


\section{Introdução}

O TVT é uma patologia que ocorre em caninos sem predisposição sexual e racial, sendo acometidos principalmente os cães errantes, cuja atividade sexual não é acompanhada (Valençola et al., 2015). Observa-se que o TVT possui distribuição mundial, apresentando-se de maneira idiossincrática benigna ou maligna (Peterson, 2008). Foi constatada maior ocorrência em países de clima quente e úmido e em locais com grande quantidade de cães que vivem soltos nas ruas, estes apresentam imunidade baixa devido estarem expostos a várias situações desfavoráveis, como exemplo a falta de alimentação balanceada (Vilaça, 2016).

Macroscopicamente, o TVT apresenta-se altamente vascularizado, muitas vezes ulcerado, de consistência friável, com aspecto semelhante a couve-flor. As lesões podem ser encontradas em maior ou menor extensão na região, genital ou extragenital. Microscopicamente, a citologia revela alta celularidade, sendo as células arredondadas ou ovóides com núcleos redondos e numerosas figuras mitóticas. As células caninas normais possuem 78 cromossomos e, as do TVT apresentam 59 cromossomos (Lorimier; Fan, 2007; Belov, 2012; Den, Hack, Jacobs, 2015).

A transmissão do TVT ocorre por contato direto durante o coito, ou mecanicamente através da pele e/ou mucosa no hábito de lamber, morder, farejar, arranhar ou qualquer outro meio de contato com animal portador. As células tumorais começam a se multiplicar de duas a três semanas após a implantação, podendo atingir a forma multilobular após um período de dois a quatro meses (Greatti et al., 2004).

Inicialmente observa-se pequenos nódulos avermelhados, com lesões superficiais que evoluem para massas multilobares. Com a evolução da doença, constata-se tecido nodular, hemorrágico e friável, com o aspecto de couve-flor, podendo haver prurido. Pequenos fragmentos do tumor apresentam pontos necróticos ou traumatizados, com coloração acinzentada (Birchard; Sherding, 1998)

Nas fêmeas, esse tumor apresenta localização caudal a vagina ou em partes vestibulares (Varughese, Singla, Ratnakaran, 2012; Akkoc et al., 2017). Nos machos, a localização anatômica padrão é na base da glande, o que exige a retração caudal peniana para identificação visual do tumor (Lorimier; Fan, 2007; Varughese, Singla, Ratnakaran, 2012), além de descargas prepuciais, bem como lambedura da região e disúria (Tinucci-Costa; Castro, 2016). No tecido cutâneo, na palpação, observa-se tumor de consistência firme, nodular, papilar ou multilobado. Na avaliação histológica há presença de células redondas ou ovóides e figuras mitóticas numerosas. No citoplasma, há vacúolos claros distintos circundados por uma membrana celular bem evidente (Petersson; Couto, 2003; Amaral et al., 2004).

O diagnóstico baseia-se no histórico do animal e, nos sinais clínicos, levando-se em consideração as características macroscópicas das lesões, além disso, deve-se realizar a confirmação através de exames complementares, como por exemplo o citológico e/ou histopatológico. O exame citológico pode ser realizado por imprint em lâmina ou por aspiração por agulha fina (PAF). O imprint é utilizado em lesões ulceradas e exsudativas onde pressiona-se a lâmina de vidro contra a lesão, e a PAF é obtida pela introdução da agulha na lesão seguida de movimentos de vai-e-vem a fim de obter maior representatividade celular. No exame citológico podem ser observadas múltiplas células redondas a ovais, com citoplasma bem delimitado, basofílico, vacuolizado, núcleo por vezes excêntrico, alta relação núcleo citoplasma e nucléolos evidentes. No exame histopatológico realiza-se a análise microscópica do tecido lesionado (Amaral et al., 2007).

A administração semanal durante o período de um mês na dose de 0,5- $0,7 \mathrm{mg} / \mathrm{m}^{2}$ ou $0,025 \mathrm{~mL} / \mathrm{kg}$ de sulfato de vincristina apresenta-se extremamente eficaz, levando a remissão completa em mais de $90 \%$ dos cães tratados (Nelson \& Couto, 2001). O sulfato de vincristina atua unindo-se a proteína tubulina, formando um inibidor da mitose, interferindo com a separação cromossômica na metáfase (Santos et al., 2011). Esse tratamento quimioterápico pode apresentar efeitos colaterais como alopecia, atraso no crescimento dos pêlos, úlcera cutânea, vômito, diarréia, constipação, insuficiência renal, reações de hipersensibilidade, toxicidade cardíaca e neurotoxidade. A radioterapia demonstrou ser efetiva nos tumores resistentes a 
quimioterapia e nos locais metastáticos. Em alguns casos pode haver necessidade da realização de citorredução neoplásica e para este fim tornam-se necessários procedimentos cirúrgicos (Sousa et al., 2000; Andrade, 2002; Brandão et al., 2002; Hedlund, 2005).

Baseado nessas informações, o objetivo neste estudo foi relatar um caso clínico de Tumor Venéreo Transmissível (TVT) na região da genitália em um cão macho na cidade de Belém, Pará.

\section{Relato de Caso}

Foi atendido um cão macho, resgatado das ruas da cidade de Belém-Pará, sem histórico clínico e sem raça definida (SRD), com aproximadamente 7 anos de idade, não castrado e peso médio de 7,5 $\mathrm{Kg}$. No exame clínico foi observado que o animal apresentava uma lesão peniana, com secreção purulenta e sanguinolenta, odor forte, e priapismo total, além de ectoparasitas, como pulgas e carrapatos (Figura 1).

Figura 1. Cão apresentando lesão na região peniana sugestiva de TVT (ponta da seta).

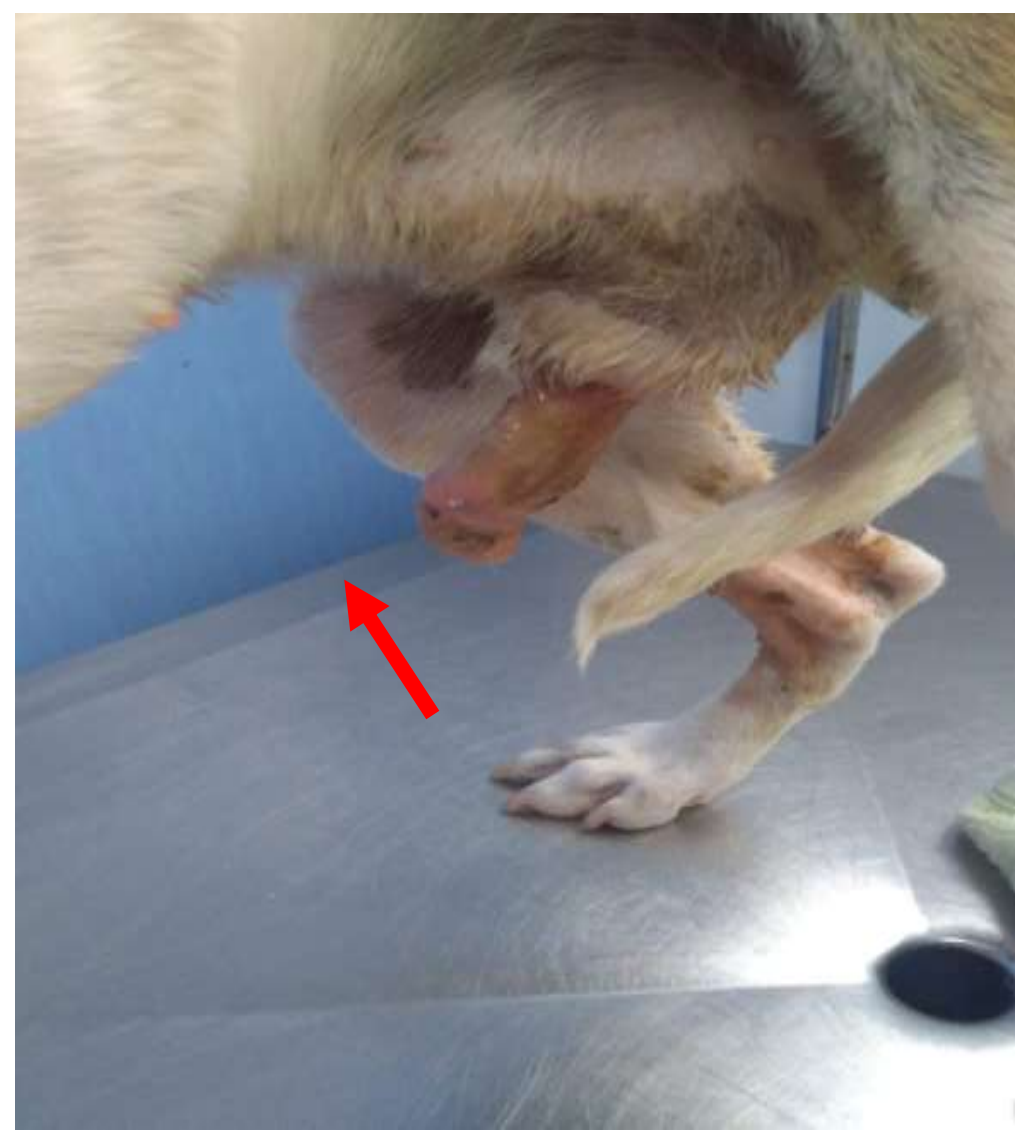

Fonte: Autores.

Levando em consideração as características da lesão, e o histórico de ser um cão errante, a principal suspeita clínica foi de TVT. Para a confirmação do diagnóstico foi realizado alguns exames complementares, como o hemograma e o citológico. $\mathrm{Na}$ análise do hemograma constatou-se que o animal apresentava hematócrito baixo, e no leucograma constatou linfopenia, neutropenia e monocitose, além de trombocitopenia (Figura 2). 
Figura 2. Resultado do hemograma.

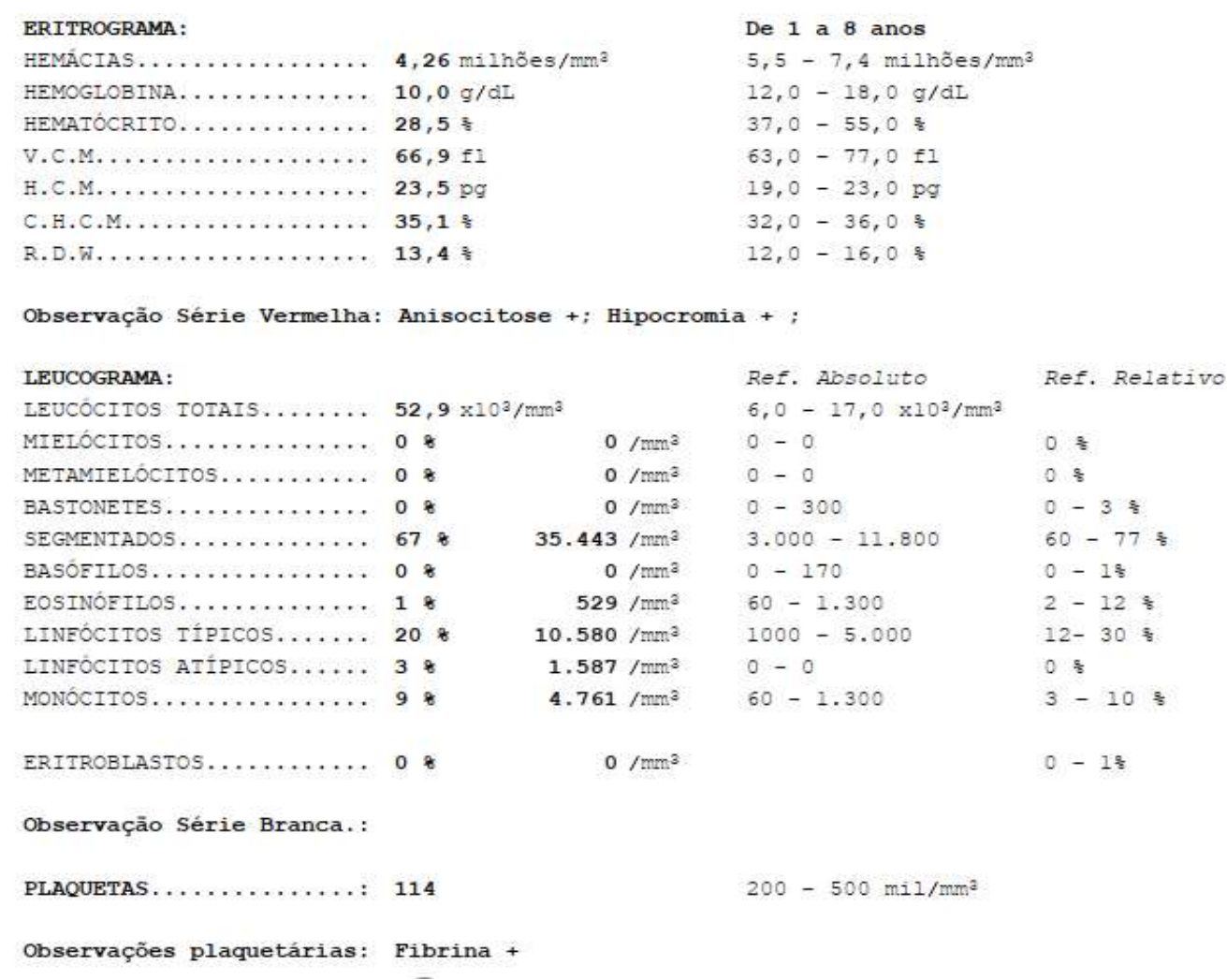

Fonte: Autores.

Por meio do exame citológico observou-se microscopicamente a presença de células arredondadas, com núcleos grandes, únicos e basofílicos, além de vacúolos, sendo estas alterações compatíveis ao padrão de TVT (Figura 3).

Figura 3. Resultado do exame citológico.

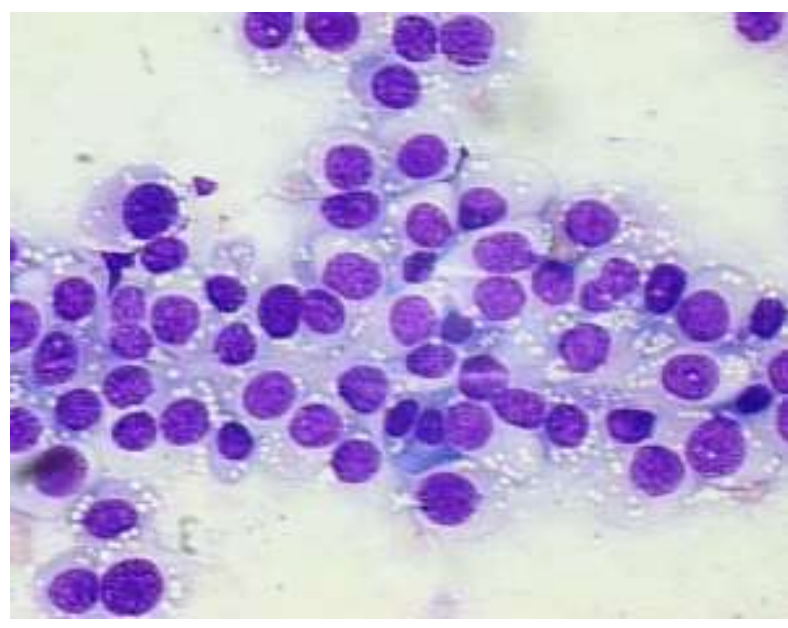

Fonte: Autores.

Para o tratamento do tumor, o quimioterápico utilizado foi o sulfato de vincristina, na dose semanal de $0.025 \mathrm{mg} / \mathrm{kg}$ por via endovenosa. Após quatro aplicações observou-se redução significativa do tumor peniano (Figura 4). 
Figura 4. Evolução da lesão durante o tratamento. (A) $1^{\mathrm{a}}$ semana de quimioterapia; (B) $2^{\mathrm{a}}$ semana; (C) $3^{\mathrm{a}}$ semana; (D) $4^{\mathrm{a}}$ semana demonstrando regressão do tumor.
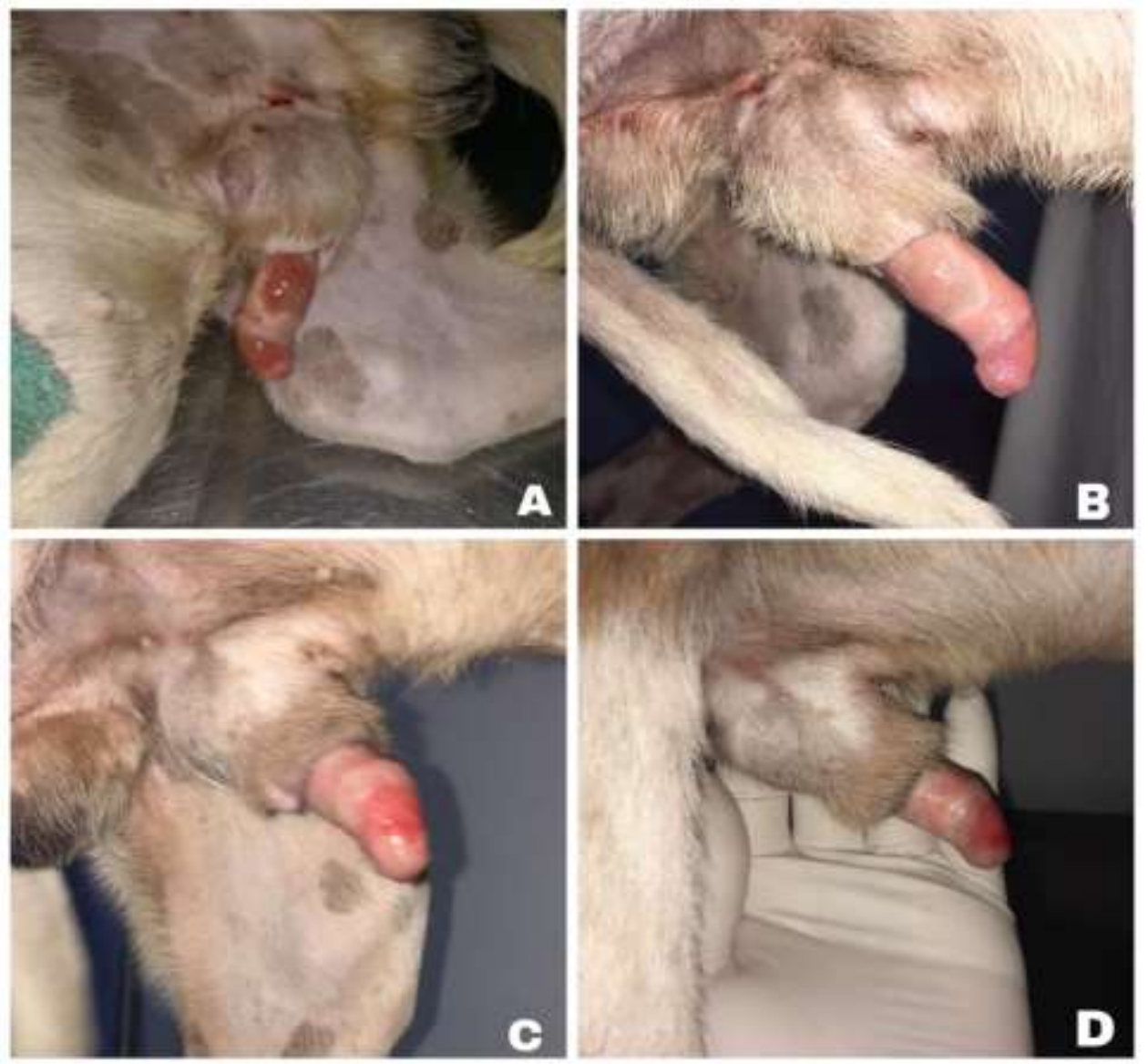

Fonte: Autores.

\section{Resultados e Discussão}

No exame hematológico foi constatado que o animal estava acometido com um vírus, e a etiologia viral do TVT foi suspeita, e alguns autores descreveram partículas virais do tipo $\mathrm{C}$ em amostras de TVT, enquanto outros pesquisadores alegaram uma possível transmissão em extratos livres de células, no entanto, tais achados não foram confirmados pela microscopia eletrônica (Murchinson et al., 2014). O hemograma revelou uma anemia e trombocitopenia devido o consumo de plaquetas, provavelmente relacionado a hemorragia e ao processo inflamatório na área tumoral, diante destes achados e a presença de ectoparasitas no animal houve suspeita da infecção por babesiose juntamente com o TVT.

De acordo com Rogers (1997), a incidência do TVT está restrita a idade de maior atividade sexual (entre dois e quatro anos de idade) e em países onde a população canina não esteja submetida a rigoroso controle epidemiológico. Neste caso a idade do animal não é compatível com o estudo, mas vale ressaltar que a população canina brasileira, não possui um rigoroso controle epidemiológico contribuindo para a disseminação de doenças, tais como o TVT.

Segundo Huppes et al. (2014), o ato social dos cães de lamber e farejar, principalmente os genitais, provocando atrito de tecidos, facilita a implantação de células neoplásicas em novos sítios, os sinais clínicos mais comuns a serem observados em casos de TVT é tecido nodular, hemorrágico e friável, com o aspecto de couve-flor conforme observado neste estudo, onde houve comprometimento peniano.

O diagnóstico desta patologia é feito, com base nos sinais clínicos, posteriormente realiza-se exames complementares, o hemograma para avaliar a saúde de maneira geral e identificar possíveis desordens, e citológico para o diagnóstico de 
neoplasias de células redondas foi recomendado por Siqueira e Malagó (2014), é bem recomendado por ser um exame simples, não invasivo e altamente confiável. Para o diagnóstico do presente estudo foram realizados os dois exames.

$\mathrm{O}$ tratamento indicado para o TVT é a quimioterapia antineoplásica utilizando como fármaco a vincristina. Jark et al. (2020) observaram que o tratamento de TVT com vincristina apresentou remissão completa em $79 \%$ dos casos relatados. Outros quimioterápicos, como, por exemplo, a actinomicina D, bleomicina, carboplatina, ciplastina, ciclofosfamida, danorrubicina e doxurrubicina, passaram por testes in vitro com o objetivo de testar seu potencial juntamente com a eletroporação, que consiste na aplicação regional de pulsos elétricos (eletroquimioterapia). No entanto, apenas a bleomicina e a ciplastina apresentaram resultados positivos para serem utilizados associados à eletroquimioterapia (Guiduce, Ranzini, Fonzar, 2013; Brunner, 2016; Cunha et al., 2017; Marelo, 2018). Apesar da bleomicina ter se mostrado eficaz, é uma droga de alto valor de mercado e de difícil acesso. Nesse contexto, surge a vincristina, um antineoplásico acessível e eficaz, sendo por isso o mais utilizado no tratamento de TVT. A vincristina, na dose semanal de $0,5 \mathrm{mg} / \mathrm{m}^{2}$ por sete semanas, mostrou-se eficaz no tratamento de uma cadela diagnosticada com TVT disseminado pelo abdômen (Groth et al., 2021).

No presente estudo, foi instituído o uso do sulfato de vincristina na dose de $0,025 \mathrm{mg} / \mathrm{kg}$ por via endovenosa, o qual se mostrou bastante eficaz, demonstrando a regressão do tumor. Além disso, a administração do fármaco para o tratamento da babesiose e do complexo vitamínico também contribui com uma resposta mais rápida ao tratamento, sendo demonstrada pela recuperação do animal.

\section{Conclusão}

Conforme observado no relato as alterações encontradas no hemograma e leucograma foram compatíveis com animais portadores de TVT, assim como o estudo citológico. O tratamento quimioterápico semanal utilizando o sulfato de vincristina na dose de $0.025 \mathrm{mg} / \mathrm{kg}$, por via endovenosa durante um mês foi capaz de ocasionar a regressão do tumor. Portanto, conclui-se que a referida droga pode ser utilizada para a terapia do TVT.

\section{Referências}

Andrade, S. F. (2002). Terapêutica antineoplásica. Manual de terapêutica veterinária, (2a ed.), Roca.

Amaral, A. S., Gaspar, L. F. J., Silva \& Rocha, N. S. (2004). Diagnostico citológico do tumor venéreo transmissível na região de Botucatu, Brasil. Revista Portuguesa de Ciências Veterinárias, 99:167-171.

Amaral, A. S., Bassani-Silva, S., Ferreira, I., Fonseca, L. S., Andrade, F. H. E., Gaspar, L. F. J., \& Rocha, N.M. (2007). Cytomorphological characterization of transmissible canine venereal tumor. Revista Portuguesa de Ciências Veterinárias, 102: 253-206.

Akkoc, A., Nak, D., Demirer, A., \& Şimşek, G. (2017). Immunocharacterization of matrix metalloproteinase-2 and matrix metalloproteinase-9 in canine transmissible venereal tumors. Biotechnic \& histochemistry: official publication of the Biological Stain Commission, 92(2):100-106.

Birchard, J., \& Sherding, R. (1998). Clínica de Pequenos Animais - Manual Saunders. Rocca.

Brandão, C. V. S. (2002). Tumor venéreo transmissível: estudo retrospectivo de 127 casos (1998-2000). Revista de educação continuada do CRMV-SP, 5, 2531.

Belov, K. (2012). Contagious cancer: lessons from the devil and the dog. Bioessays.

Duncan, J.; Prasse, K. (1982). Patologia clínica veterinária. UFSM.

Den, O. W., Hack. M. \& Jacobs, J. J. (2015). Effective treatment of transmissible venereal tumor in dogs with vincristine and IL2. Anticancer Research.

Brunner, C. H. (2016). Eletroquimioterapia. In: Dalek, C. R; De Nardi. A. B. Oncologia Em Cães e Gatos. (2a ed.), Roca. 766. p. $380-392$.

Cemazar, M., Tamzali, Y., Sersa, G., Tozon, N., Mir, L. M., Miklavcic, D., Lowe, R., \& Teissie, J. (2008). Electrochemotherapy in Veterinary Oncology. Journal of Veterinary Internal Medicine, 22, (4), 826-831.

Cunha, R. M. C., Lavalle, G. E., Reis, D. C., Horta, R. S., Teixeira, S. V., Ramirez, J. A., \& Araújo, R. B. (2017). Assessment of electrochemotherapy effects on the development of Ehrlich solid tumor in swiss mice using a novel electroporator device. Arquivo Brasileiro de Medicina Veterinária e Zootecnia, 69(6), 1581- 1590 . 
Ferreira Neto, J. M., Viana, J. M. M. E. S. \& Magalhães, L. M. (1977). Patologia clínica veterinária. Rabelo e Brasil.

Greatti, W. F. P., Amaral, A. S., Silva, S. B., Gaspar, L. F. J., Barbisan, L. F., \& Rocha, N. S. (2004). Índices proliferativos do tumor venéreo canino transmissível pelas técnicas do CEC e KI-67 na citologia aspirativa com agulha fina. Archives of Veterinary Science, 9(1), 53-59.

Groth, A., Silva, L.A.S., Martins, M.I.M., Fernandes, M.P., Greghi, J. R., Amaral, L. M. S., Silva, V. W., Aguiar, A., Bracarense, A. P. F. R. L. (2021). Transmissible veneral tumor in a dog's abdominal cavity: Uncomm on report. Research, Society and Development, 10(8), e0110816429, 2021.

Guiduce, M, V. S., Ranzini, J, J. T., \& Fonzar, J. F. (2013). Eletroquimioterapia em cães e gatos. Revista CFMV, .60, $59-61$.

Hedlund, C. S. (2005). Cirurgia do sistema reprodutivo e genital. In: FOSSUM, T.W. Cirurgia de pequenos animais, (2a ed.), Roca.

Huppes, R. R., De Nardi, A. B., Raposo, T. M. M., Passos, B. L. S., Daleck, C. R., Silva, A. R., Brum, A. M., \& Taguchi, T. M. (2010). Utilização da Bleomicina no tratamento de um TVT resistente a Vincristina e Doxorrubicina. http://www.sovergs.com.br/BKP/site_/38conbravet/resumos/192.pdf.

Huppes, R. R., Silva, C. G., Uscategui, R. A. R., De Nardi, A. B., Souza, F. W., Costa, M. T., Amorim, R. L., Pazzini, J. M. \& Faria, J. L. M. (2014). Tumor venéreo transmissível (TVT): Estudo retrospectivo de 144 casos. ARS Veterinaria, 30(1), 013-018.

Jark, P. C., Barros, F. S., Matiz, O. R. S., Sueiro, F. A. R. Costa, M. T., Dias, F. G. G. (2020). Nosological and retrospective study of cases of extragenital transmissible venereal tumor in dogs. Research, Society and Development, 9(10), e2419108359.

Lorimier, L. P., \& Fan, T. M. (2007). Miscelaneus Tumors. In: Withrow, S. J., Vail, D. M., Page, R. L. Witrow \& Macewens Small Animal Clinical Oncology. (4a ed.), Elsevier.

Lapa, F. A. S. (2009). Estudo comparativo da eficácia de dois protocolos de tratamento do tumor venéreo transmissível em cães. 2009 , 73 f. Dissertação (Mestrado) Universidade do Oeste Paulista. Presidente Prudente.

Murchison, E. P., Wedge, D. C., \& Alexandrov, L. B. (2014). Transmissible dog cancer genome reveals the origin and history of an ancient cell lineage. Science, 343(6169), 437-440.

Marelo, B. R. S. (2018). A eletroquimioterapia no tratamento de neoplasias em gatos. 2018. 45f. Tese (Mestrado integrado em Medicina Veterinária) - Escola Universitária Vasco Da Gama, Coimbra, PT.

Nelson R. W., \& Couto C. G. (2001). Medicina interna de pequenos animais. (2a ed.), Guanabara Koogan.

Peterson, J. L., \& Couto, C. G. (2003). Tumores cutâneos e subcutâneos. In: Birchard, S.J.; Sherding, R.G. Manual saunders clínica de pequenos animais. 2 ed. São Paulo: Roca.

Peterson, J. L. (2008). Tumores cutâneos e subcutâneos. In: Birchard, S. J., Sherding, R. G. Manual Saunders Clínica de Pequenos Animais. 3 ed. São Paulo: Roca, 2008.

Rogers, K. S. (1997). Transmissible venereal tumor. The Compendium on Continuing Education for the Practicing Veterinarian, 19(9), 1036-1045.

Rodaski, S., \& De Nardi, A. B. (2006). Classificação dos quimioterápicos. In: Rodaski, S.; De Nardi, A. B. Quimioterapia Antineoplásica em Cães e Gatos. Curitiba: Bio.

Sousa, J., Saito, V., Nardi, A. B., Rodaski, S., Guérios, S. D., \& Bacila, M. (2000). Características e incidência do tumor venéreo transmissível (TVT) em cães e eficiência da quimioterapia e outros tratamentos. Arquivos de Ciências Veterinárias da Universidade Federal do Paraná, 5, 41-48.

Santos, I. F. C., Cardoso, J. M. Da M., \& Oliveira, K. C. (2011). Metástases cutâneas de tumor venéreo transmissível canino - Relato de caso. Revista Científica de Medicina Veterinária, 9(31), 639-645.

Siqueira, N., \& Malagó, R. (2014). Características morfométricas de células neoplásicas de tumor venéreo transmissível canino (TVTC). Revista Científica da FEPI, 6, 1-4.

Tinucci-Costa, M. T. (2009). Tumor venéreo transmissível canino. In: Daleck, C. R.; De Nardi, A. B.; Rodaski, S. Oncologia em Cães e Gatos. São Paulo: Roca.

Tinucci-Costa, M., \& Castro, K. F. (2016). Tumor venéreo transmissível canino. In: Daleck, C. R., Nardi, A. B. Oncologia em cães e gatos. (2a ed.), Rocca.

Varughese, E., Singla, V., \& Ratnakaran, U. (2012). Successful management of metastatic transmissible venereal tumour to skin of mammary region. Reproduction in Domestic Animmal, 47, 366-369.

Valençola, R. A., Antunes, T. R., Sorgatto, S., Oliveira, B. B., Godoy, K. C. S., \& Souza, A. I. (2015). Aspectos citomorfológicos e frequência dos subtipos do tumor venéreo transmissível canino no município de Campo grande, Mato Grosso do Sul, Brasil. Acta Veterinaria Brasilica. 9(1), 82-86.

Vilaça, M. R. (2016). Ocorrência de Tumor Venéreo Transmissível (TVT) em Cães Atendidos na Clínica de Medicina Veterinária (CLIMVET) do UNIFOR $M G$, entre os anos de 2011 a 2015. 